\title{
Reenactment of a bollard pull test for a double propeller tugboat using computational fluid dynamics
}

Recreación de la prueba de Tracción a punto fijo de un remolcador de doble propulsor mediante dinámica de fluidos computacional

\begin{abstract}
Use of CFD simulations is an affordable and trustworthy way of determining a vessel's capacity before its construction. This study focuses in simulating a bollard pull of a specific tugboat and comparing the results with those of the real test to which it was subjected after construction. In compliance with the regulations of the classification societies regarding these types of tests, simulations will be carried out to study the bollard pull tests of a double propeller two boat. The results showed that the mathematical model is suitable for a numerical calculation of the bollard pull tests.
\end{abstract}

Key words: Bollard pull test, tugboat, power, simulation, modelling, computational fluid dynamics.

\section{Resumen}

La utilización de simulaciones CFD es un modo económico y fiable de determinar las capacidades de un buque antes de su construcción. Este estudio está enfocado a simular la prueba de tracción a punto fijo de un remolcador específico y comparar los resultados obtenidos con los de la prueba real a la que fue sometido después de su construcción. Atendiendo a la normativa de las sociedades de clasificación sobre este tipo de pruebas, se realizarán simulaciones para estudiar la prueba de tracción a punto fijo de un remolcador de doble propulsión. Los resultados obtenidos demostraron que el modelo matemático es apto para realizar de forma numérica las pruebas de tracción a punto fijo (bollard pull).

Palabras claves: Prueba de tracción a punto fijo, remolcadores, potencia, simulación, modelado, mecánica de fluidos computacionales

Date Received: October 10th, 2014 - Fecha de recepción: 10 de octubre de 2014

Date Accepted: March 19th, 2015 - Fecha de aceptación: 19 de marzo de 2015

\footnotetext{
${ }^{1}$ Laboratorio Especializado en Procesos de Unión y Manufactura (LEPUM). ), Universidad Tecnológica de Panamá. Panama. Email: adan.vega@utp.ac.pa

${ }^{2}$ Facultad de Náutica de Barcelona, Universidad Politécnica de Cataluña. España. Email:
} 


\section{Introduction}

Currently, vessel pull tests are performed using bollard pull tests. Performing these tests requires that the vessel is already built, so that when performing said test compliance with previously established pulling requirements is verified. If the vessel does not comply, going back to the drawing table to make the necessary adjustments to solve the problem is required, which results in additional costs. It is therefore obvious to conclude that developing a methodology that allows verifying the vessel's pulling capacity during the design stages and thus performing a simulation that can predict the behavior during real bollard pull tests once the vessel is built, would be a very useful tool It is widely known that propeller studies have been done for years using different methods; in most cases it is very difficult to perform a precise analysis, but thanks to advances in information systems this capacity has drastically increased, and is increasing thanks to the use of computational tools in different fields of study, one of them being propeller analysis [1], were the use of simulations using specialized software has become very popular thanks to their versatility that allows to perform study models without the need to physically build them. This results in important financial savings when performing a particular study. Computational fluid dynamics (CFD) is being used in several naval area studies [2], were CFD solution methods have been introduced, such as the Reynolds Averaged Navier-Stokes (known as RANS) [3], which allows for complex solutions of Navier-Stokes equations, in most cases impossible to solve manually.

J. Martinez de la Calle et al. (4) developed two methodologies, a numerical and an experimental one, for the study of flow around a marine propeller, performed a flow analysis that presents the non-dimensional characteristic curves or propeller diagram of a marine propeller; obtained both experimentally as well as using numerical simulation techniques. They used a reduced scale propeller model and after developing the methodologies that correspond to both techniques (numerical and experimental) achieved very similar results, indicating the validity of a numerical technique (CFD) as well as the design and flow analysis of a marine propeller.

Isao Funeno (5) used computational fluid dynamics for the hydrodynamic analysis of azimuth propellers, taking into consideration uncompressible viscous fluid, used the SST k- $\omega$ turbulence model with wall function. The effect in the flow field of the propeller was taking into consideration introducing centrifugal forces and coriolis forces in a system of coordinates relative to the body's forces using the formulas with Reynolds' averages of the Navier-Stokes equations. From a hydrodynamic point of view, the analysis of azimuth propellers is more complicated than that of conventional propellers given the strong interaction between the propeller and the duct; also, one of the most complicated conditions to analyze is bollard pull. Due to this inconvenience, Kawasaki Heavy Industries (6) has performed water tank tests using small and sophisticated waterproof dynamometers to improve the analysis.

W.H. Lam et al., (7) performed a study using the Reynolds' average of the Navier-Stokes equations (RANS) using computational fluid dynamics to predict water flow through a propeller and compared the turbulence models with the experimental results obtained. The turbulence models used were those of the Boussinesq family, using the standard $\mathrm{k}-\varepsilon$ model, RNG $\mathrm{k}-\varepsilon$, realizable $\mathrm{k}-\varepsilon$, standard k- $\omega$, SST $\mathrm{k}-\omega$ and the SpalartAllmaras model, subsequently presenting the advantages and inconveniences of one model over another.

Some bollard pull studies have been performed using computational methods (8) but none of them have taken into consideration the pull generated by the set of propeller, duct and interaction with the hull.

The authors have developed a methodology to perform the bollard pull test analysis using computational fluid dynamics which has obtained similar results to those obtained from real environment tests. This article presents the mathematical model that was developed. The results after simulating the hull of a double 
propeller tugboat are presented and discussed. Finally, a comparison between the numerical results and those obtained using existing equations are compared.

\section{Description of the bollard pull test}

Bollard pull tests are performed in order to obtain the static pull that a vessel can attain; during this test, the vessel is grounded so it cannot move over the water and therefore has a forward speed equivalent to zero. A device is used to measure force, which can be a dynamometer, a charge cell or a strain gauge. The pull generated depends greatly on displacement, hull shape, as well as the type of propeller and power. This test is applied to different types of vessel, mainly to measure pull for tugboats, where this condition is quite similar to their operations, such as towing or pulling vessels or floating artifacts at very low speeds.

\section{Mathematical model}

\section{Fluid properties}

To develop this study, the properties of the fluid used within the computational domain are presented initially, in this case sea water under standard conditions of $20^{\circ} \mathrm{C}$, a Newtonian fluid. In the tangential flow of Newtonian fluids, shear strength known in fluid mechanics as viscous stress is governed by the following equation:

$$
\tau=\mu \frac{d \theta}{d t}
$$

where $\mu$ is dynamic viscosity, and $\frac{d \theta}{d t}$ is the stress yield.

\section{Fundamental fluid equations}

The equations that describe the behavior of any fluid are those of continuity and amount of movement. During this investigation the assumption of an isothermal fluid will be made since temperature changes are very small. This constant temperature consideration eliminates the need to implement an additional variable, temperature, which is the reason why the differential equation of energy conservation is not introduced. The fundamental equation originates any fluid analysis and is the continuity equation resulting from:

$$
\frac{D \rho}{D t}+\nabla \cdot(\rho \vec{V})=0
$$

where:

$$
\begin{aligned}
& \frac{D \rho}{D t}=\frac{\partial \rho}{\partial t}+u \frac{\partial \rho}{\partial x}+v \frac{\partial \rho}{\partial y}+w \frac{\partial \rho}{\partial z} \\
& \nabla \cdot(\vec{V})=\frac{\partial u}{\partial x}+\frac{\partial v}{\partial y}+\frac{\partial w}{\partial z}
\end{aligned}
$$

The continuity equation describes mass conservation within a control volume. This case study the fluid is treated as uncompressible and thus the continuity equation is simplified as follows:

$$
\nabla \cdot(\vec{V})=0
$$

The second important equation in this analysis is the amount of movement equation defined by:

$$
\frac{D(\rho \vec{V})}{D t}=\nabla \cdot \bar{\sigma}+\rho \vec{g}
$$

where:

$$
\frac{D V}{D t}=\frac{\partial \vec{V}}{\partial t}+u \frac{\partial \vec{V}}{\partial x}+v \frac{\partial \vec{V}}{\partial y}+w \frac{\partial \vec{V}}{\partial z}
$$

The amount of movement equation does not sole the fluid mechanics issues since it is not mathematically solvable. This is due to the fact that it needs to express stress yield $\bar{\sigma}$ in terms of primary variables, that is, density, pressure and speed. In order to achieve an analytical solution to the so called constitutive equations are introduced which allow expressing stress yield as a function of speed and pressure, as follows:

$$
\begin{aligned}
& \sigma_{i j}=-p \delta_{i j}+\tau_{i j} \\
& \tau_{i j}=2 \mu D_{i j}-\frac{2}{3} \mu \nabla \cdot(\vec{V}) \delta_{i j}\left[\begin{array}{lll}
\tau_{x x} & \tau_{y z} & \tau_{z x} \\
\tau_{x y} & \tau_{y y} & \tau_{z y} \\
\tau_{x z} & \tau_{y z} & \tau_{z z}
\end{array}\right]
\end{aligned}
$$


where:

$$
D_{i j}=\frac{1}{2}\left(\frac{\partial v_{i}}{\partial j}+\frac{\partial v_{j}}{\partial i}\right)
$$

is the viscous stress yield and

$$
\sigma_{i j}=\left[\begin{array}{lll}
1 & 0 & 0 \\
0 & 1 & 0 \\
0 & 0 & 1
\end{array}\right]
$$

component is known as Kronecker delta. This way, the constitutive equation for Newtonian fluids is simplified as follows.

$$
\sigma_{i j}=-p \delta_{i j}+\mu\left(\frac{\partial v_{i}}{\partial j}+\frac{\partial v_{j}}{\partial i}-\frac{2}{3} \nabla \cdot(\vec{V}) \delta_{i j}\right)
$$

After replacing the constitutive equation, the Navier-Stokes equations are obtained, which represent the basis for fluid mechanics:

$$
\begin{aligned}
\frac{D(\rho u)}{D t}= & -\frac{\partial p}{d x}+\mu\left(\frac{\partial^{2} u}{\partial x^{2}}+\frac{\partial^{2} u}{\partial y^{2}}+\frac{\partial^{2} u}{\partial z^{2}}\right) \\
& +\frac{\mu}{3} \frac{\partial}{\partial x}\left(\frac{\partial u}{\partial x}+\frac{\partial v}{\partial y}+\frac{\partial w}{\partial z}\right)+\rho g_{x} \\
\frac{D(\rho v)}{D t}= & -\frac{\partial p}{d y}+\mu\left(\frac{\partial^{2} v}{\partial x^{2}}+\frac{\partial^{2} v}{\partial y^{2}}+\frac{\partial^{2} v}{\partial z^{2}}\right) \\
& +\frac{\mu}{3} \frac{\partial}{\partial y}\left(\frac{\partial u}{\partial x}+\frac{\partial v}{\partial y}+\frac{\partial w}{\partial z}\right)+\rho g_{y} \\
\frac{D(\rho w)}{D t}= & -\frac{\partial p}{d z}+\mu\left(\frac{\partial^{2} w}{\partial x^{2}}+\frac{\partial^{2} w}{\partial y^{2}}+\frac{\partial^{2} w}{\partial z^{2}}\right) \\
& +\frac{\mu}{3} \frac{\partial}{\partial z}\left(\frac{\partial u}{\partial x}+\frac{\partial v}{\partial y}+\frac{\partial w}{\partial z}\right)+\rho g_{z}
\end{aligned}
$$

For uncompressible fluids the Navier-Stokes equations are simplified to:

$$
\begin{aligned}
& \frac{\rho D(u)}{D t}=-\frac{\partial p}{d x}+\mu\left(\frac{\partial^{2} u}{\partial x^{2}}+\frac{\partial^{2} u}{\partial y^{2}}+\frac{\partial^{2} u}{\partial z^{2}}\right)+\rho g_{x} \\
& \frac{\rho D(v)}{D t}=-\frac{\partial p}{d x}+\mu\left(\frac{\partial^{2} v}{\partial x^{2}}+\frac{\partial^{2} v}{\partial y^{2}}+\frac{\partial^{2} v}{\partial z^{2}}\right)+\rho g_{y} \\
& \frac{\rho D(w)}{D t}=-\frac{\partial p}{d x}+\mu\left(\frac{\partial^{2} w}{\partial x^{2}}+\frac{\partial^{2} w}{\partial y^{2}}+\frac{\partial^{2} w}{\partial z^{2}}\right)+\rho g_{z}
\end{aligned}
$$

The analytical solution of the Navier-Stokes equations results almost impossible for vessel and propeller flow. There are several mathematical models that allows simplifying phenomena such as viscosity and turbulence. One of the most commonly used models are the Averaged NavierStokes (RANS). This method takes the variables and divides them in two components; the mean or average component, and the fluctuation component, as shown in the following equation:

$$
u_{i}=\overline{u_{i}}+u_{i}
$$

Where: $\bar{u}_{i}$ is the mean component and $u_{i}^{\prime}$ is the fluctuation component.

This model adds the Navier-Stokes equations in a term known as Reynolds stress; thanks to this term it is possible to achieve a numerical solution applying a turbulence model. The following equation shows the solution, better known as Averaged Navier-Stokes equations:

$$
\begin{aligned}
\frac{\rho D(u)}{D t}= & -\frac{\partial p}{d x}+\mu\left(\frac{\partial^{2} u}{\partial x^{2}}+\frac{\partial^{2} u}{\partial y^{2}}+\frac{\partial^{2} u}{\partial z^{2}}\right) \\
& +\rho g_{x}-\rho\left(\left(\overline{u^{\prime} u^{\prime}}\right)_{x}+\left(\overline{u^{\prime} v^{\prime}}\right)_{y}+\left(\overline{u^{\prime} w^{\prime}}\right)_{z}\right) \\
\frac{\rho D(v)}{D t}= & -\frac{\partial p}{d y}+\mu\left(\frac{\partial^{2} v}{\partial x^{2}}+\frac{\partial^{2} v}{\partial y^{2}}+\frac{\partial^{2} v}{\partial z^{2}}\right) \\
& +\rho g_{y}-\rho\left(\left(\overline{v^{\prime} u^{\prime}}\right)_{x}+\left(\overline{v^{\prime} v^{\prime}}\right)_{y}+\left(\overline{v^{\prime} w^{\prime}}\right)_{z}\right) \\
\frac{\rho D(w)}{D t}= & \frac{-\partial p}{d y}+\mu\left(\frac{\partial^{2} w}{\partial x^{2}}+\frac{\partial^{2} w}{\partial y^{2}}+\frac{\partial^{2} w}{\partial z^{2}}\right) \\
& \left.+\rho g_{y}-\rho\left(\overline{\left(w^{\prime} u^{\prime}\right.}\right)_{x}+\left(\overline{w^{\prime} v^{\prime}}\right)_{y}+\left(\overline{w^{\prime} w^{\prime}}\right)_{z}\right)
\end{aligned}
$$

Curve of characteristic coefficients of propellers s

Fig. 1 shows a typical open water diagram. These diagrams describe the specificities and characteristics of propellers for a variety of advances, rotation speeds, fluid density and propeller diameters. The diagrams present defined lines for the propeller pass relation $(\mathrm{P} / \mathrm{D})$; these lines are applicable to various propeller diameters as long as the same geometric shape is kept, defined by the characteristic curve that also works for any other 
fluid. When using the pull and torque coefficients defined in these diagrams, the propeller diameter and fluid density of the operation medium must be determined. Then, when the advance and rotation speed is established the advance coefficient is obtained $(\mathrm{J})$; then a vertical line is drawn from the advance coefficient that intercepts the pass relation curve $\mathrm{Kt}$ for the thrust coefficient and $\mathrm{Kq}$ for the torque coefficient; once these operations are performed the thrust as well as the theoretical torque generated by the propeller are found. Below are the equations describing the open waters diagrams:

\section{Advance Coefficient:}

$$
J=\frac{V_{a}}{n D}
$$

where $V_{a}$ is the advance speed, which is equal to zero in the Bollard Pull condition, therefore in our case study $J=0$ thrust coefficient:

$$
K_{T}=\frac{T}{\rho n^{2} D^{4}}
$$

where $T$ is thrust force. For the case of propellers with ducts the thrust coefficient is the sum of the thrust coefficient of the propeller and the thrust coefficient of the duct. In $K_{T}$ is equal to 0.525 .

\section{Torque coefficient:}

$$
K_{Q}=\frac{Q}{\rho n^{2} D^{5}}
$$

where $Q$ is the propeller torque in our case $K_{Q}$ equals 0.044 .

\section{Simulation of bollard pull test us- ing CFD}

\section{Generation of the tridimensional hull model}

The first step in performing the bollard pull test is developing the tridimensional hull model of the vessel. The Rhinoceros 3D software was chosen for this effect. It is a software tool for 3D modelling, based on NURBS surfaces that allows including a file of the bitmap as a basis for drawing the water

Fig. 1. Diagram of thrust coefficients, torque coefficients and propeller efficiencies Ka 4-70 with 19A ducts [9].

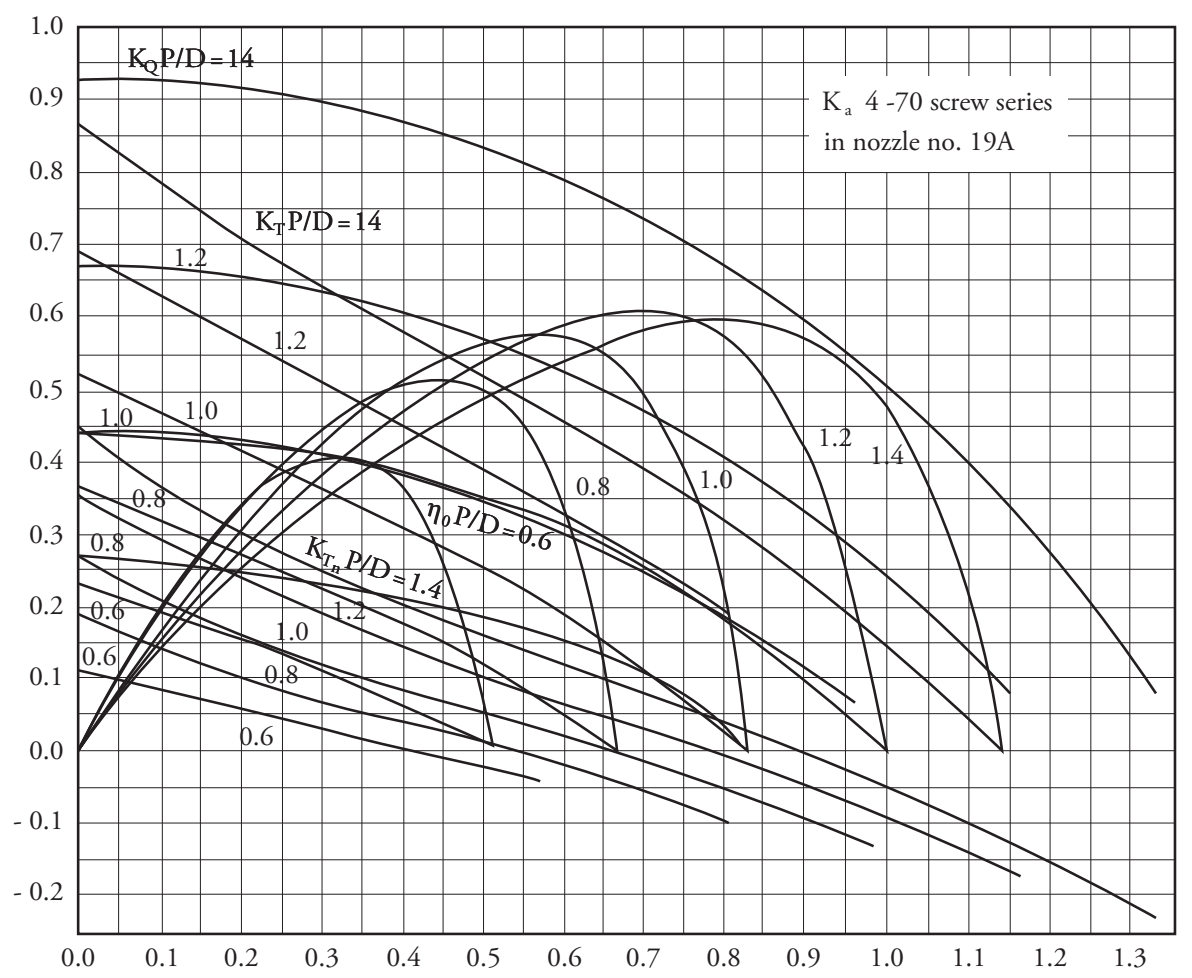


lines, frames and other shapes of the tugboat's hull. Fig. 2 shows the different sections of the shape for the tugboat selected for the study. After a series of operations, the $3 \mathrm{D}$ model was transformed into a mathematical model of finite elements that can be used in the ANSYS software, which we used for our simulations. The tridimensional hull model and its annexes are shown in Fig. 3.

Fig. 2. Sections of hull shapes.

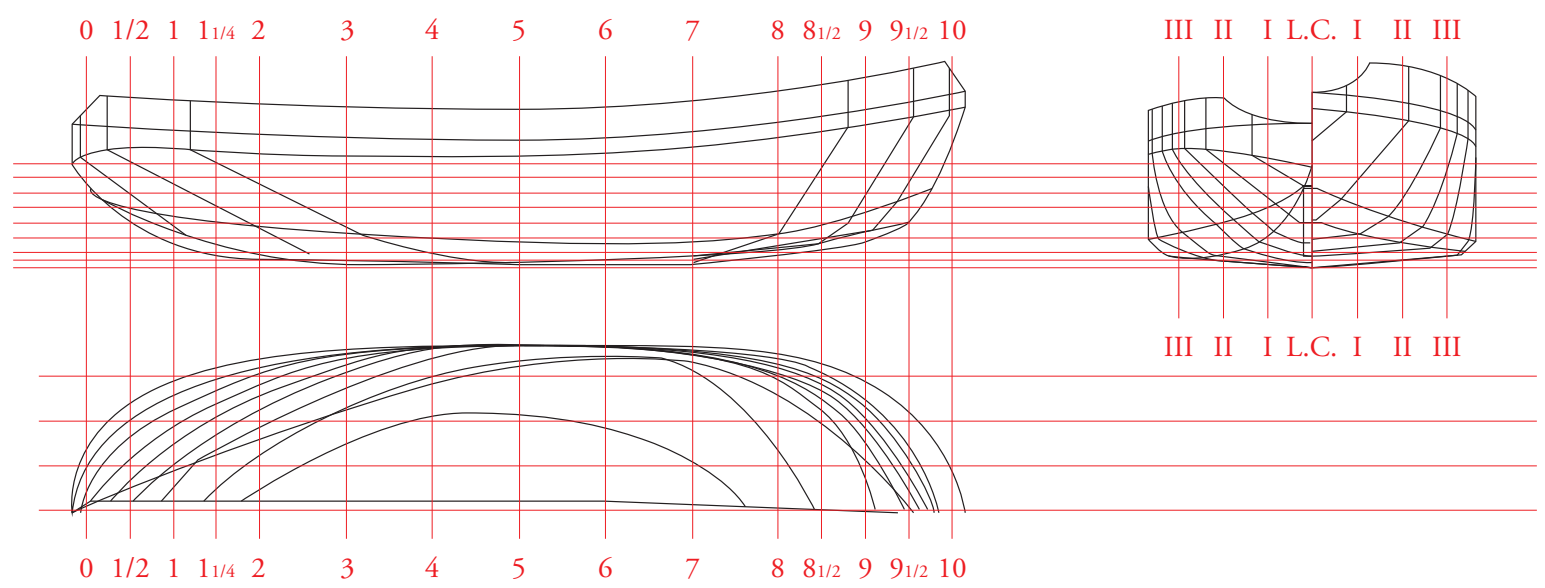

Fig. 3. Tridimensional model of the hull used in the simulation.

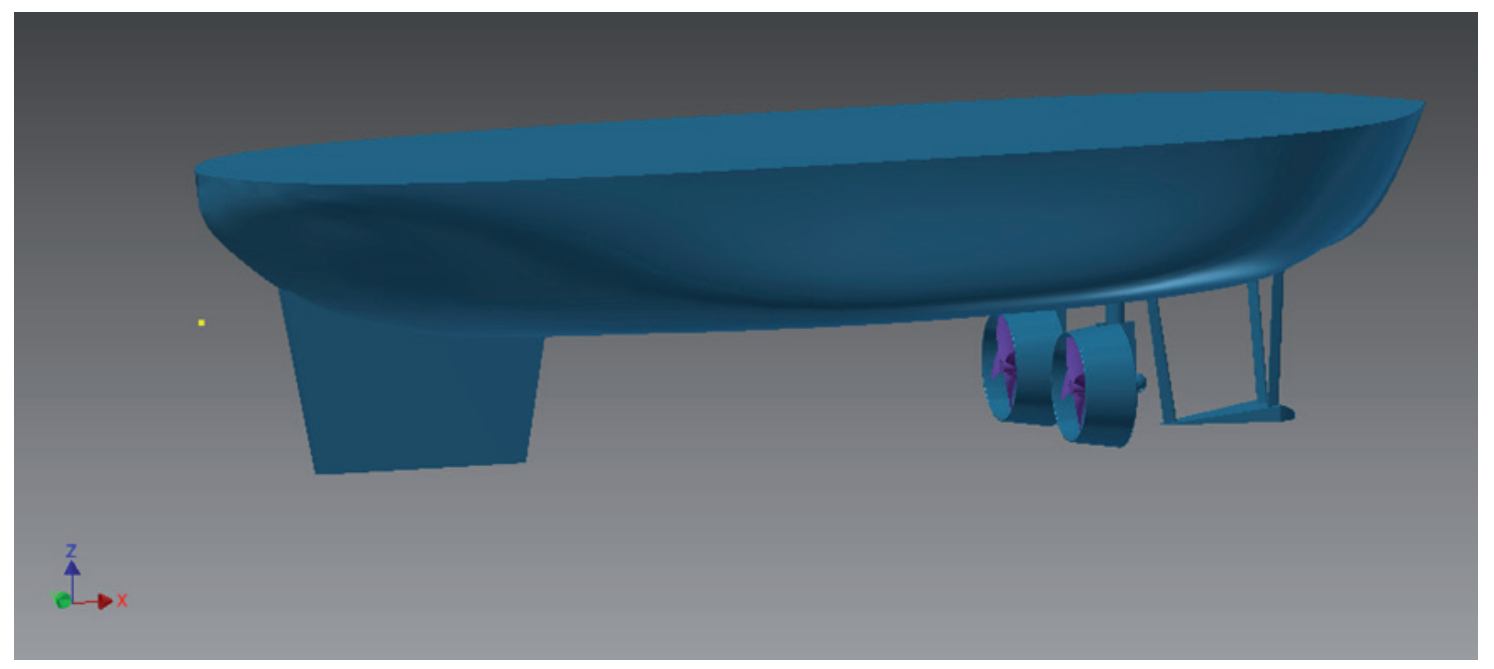

\section{Selection of propulsion system}

In our case the selected tugboat uses a double propulsion system where one of the propellers will be dextrogyre. The shape of the blades is obtained from the manufacturer and belongs to the Ka series [5], as shown in Fig. 4.

\section{Meshing of the finite elements model}

An unstructured tetrahedral meshing was used in the Patch Independent mode, which initially creates the mesh in the domain surfaces and then the boundaries, opposite to the Patch Conforming mode which first 
Fig. 4. Shape of propeller blades series [5].
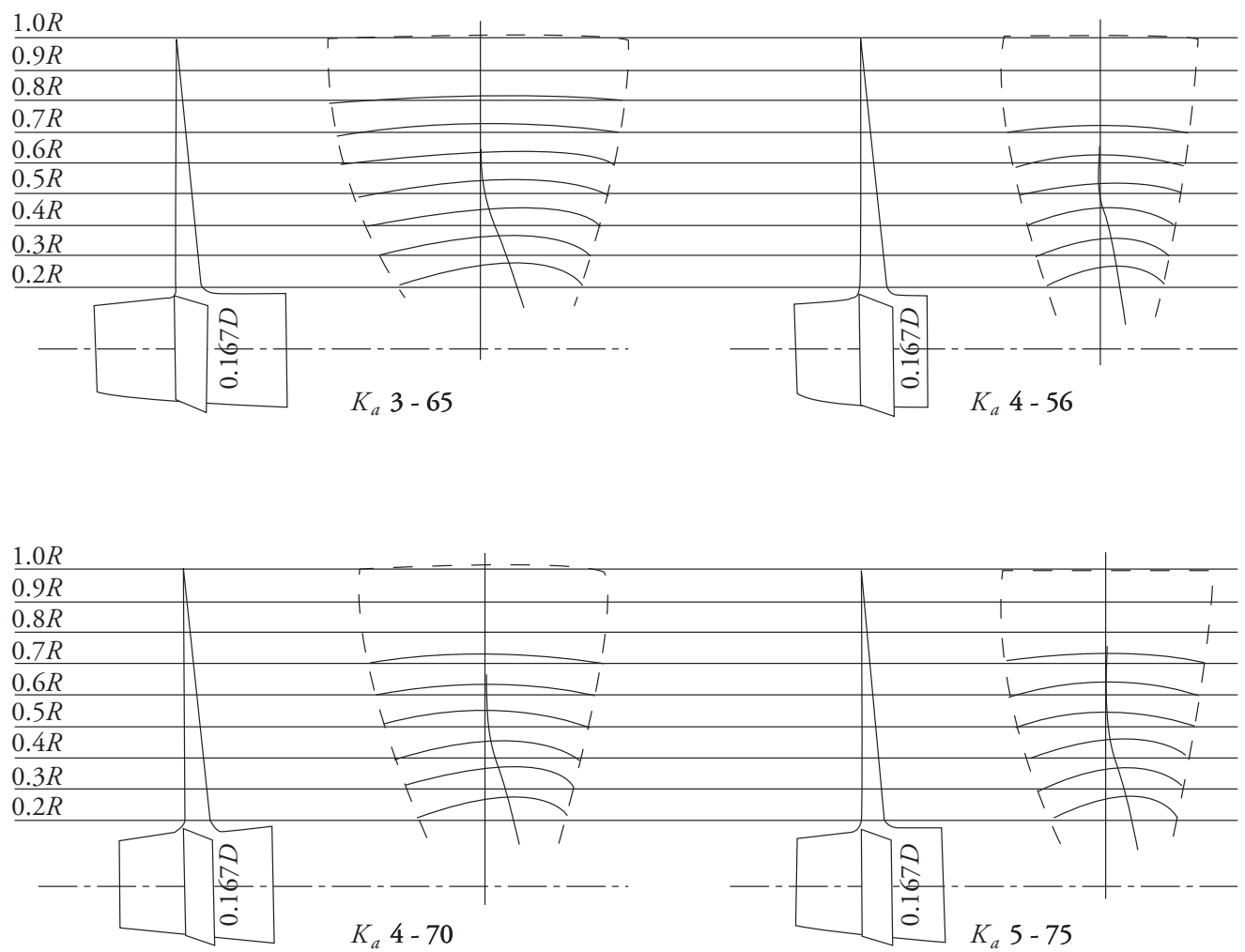

$\rho=$ uniform

creates the boundaries and then the surfaces. The asymmetry known as skewness is reduced in this way while at the same time the quality of the meshing is increased. The area with the greatest asymmetry is the propeller area due to its complex geometry; a meshing of asymmetry of less than 0.75 is recommended to obtain acceptable meshing and achieve a realistic simulation; in our case, a maximum asymmetry of 0.6948 was obtained in the computational domain. Fig. 5 shows details of the model's meshing and its main components.

Fig. 5. Meshing of the model of the tugboat: a) duct and propeller set, b) propeller.

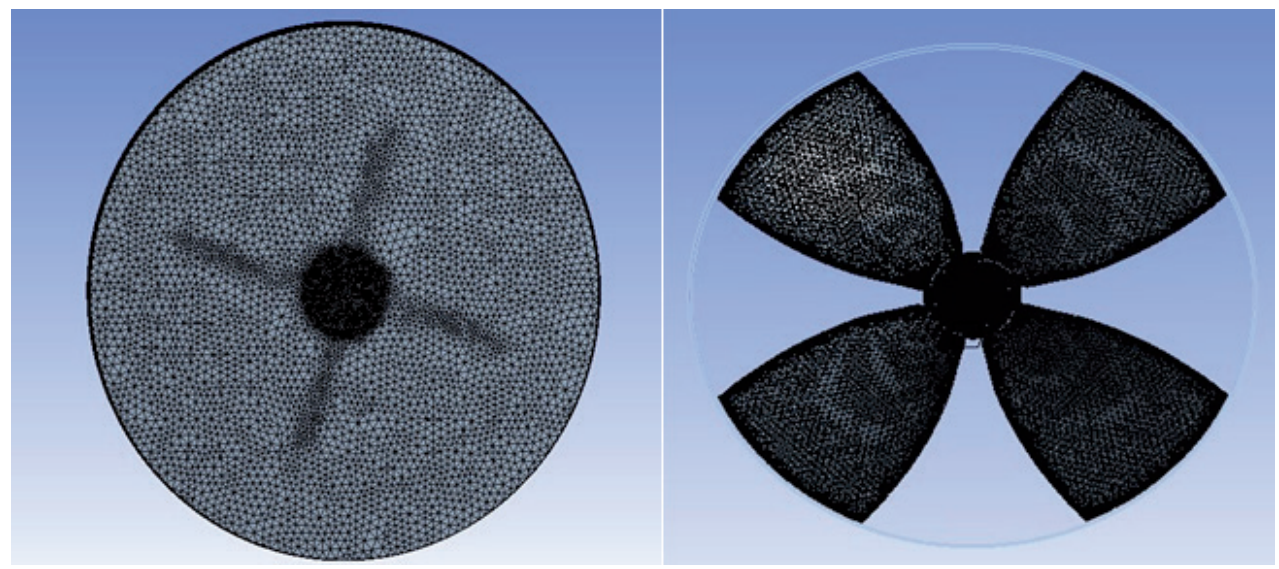


Fig. 5. c) Hull, duct and propeller set.

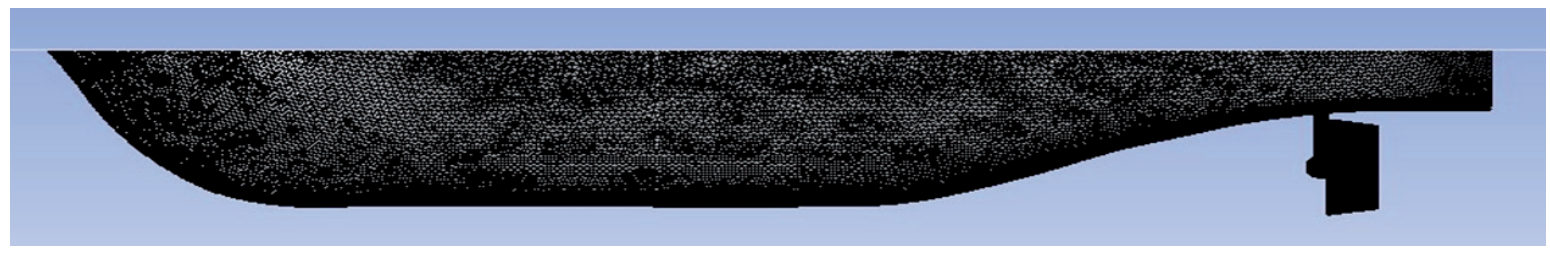

\section{Boundary conditions}

Development of computational fluid dynamics simulations requires establishment of boundary condition for the domain. These have been selected to achieve an environment that is closest to the real environment, achieving an appropriate ratio between the fluids and the vessel's components. The boundary conditions represent a fundamental aspect to develop the Navier-Stokes equations, fulfill the continuity equation and achieve convergence of the simulation. For this analysis the following boundary conditions were used: (1) boundary condition for the water surface: established as symmetry given that the surface is not a real wall and therefore there are no viscous stresses on it; also there is no convective fluid through the plane of symmetry since there is no mass transport over this surface, which is why the normal velocity component is equal to zero. There is also no diffuse fluid on this surface, so the normal gradients of the flow variables are also equal to zero. (2) Boundary condition for the entire vessel: a no slip wall boundary condition was selected. This means that the fluid movement does not fully stop at the surface and achieves a speed of zero in relation to it. A fluid in direct contact with a solid sticks to the surface due to viscous stress. The fluid property that affects the no slip condition is viscosity. Therefore, for these no slip surfaces $V \cdot n=0$. Where $\mathrm{V}$ is the fluid speed in relation to the surface and $\mathrm{n}$ is a normal unit vector of the surface. (3). The sea bottom boundary condition: the boundary condition established at the sea bottom is also a no slip condition, this boundary is close to a flat wall. This condition was selected since the sea bottom is a real surface and is therefore subjected to viscous stress. (4) Domain limits boundary condition: the boundary condition established for the sides, the front and back of the computation al domain is the pressure outlet $=0$ condition. At first sight establishing this condition might seem as a mistake, but the Ansys Fluent software redefines pressure in terms of modified pressure including the hydrostatic effects as follows: Modified pressure: $P^{\prime}=P-\rho_{o} \vec{g} \cdot \vec{r}$ where $P$ is conventional pressure, $\rho_{o}$ is constant reference density $\vec{g}$ is the gravity vector and $\vec{r}$ is the position vector. Conventional hydrostatic pressure for a fluid is equal to $P=\rho \vec{g} \cdot \vec{r}$ where $\rho$ is equal to the fluid density. Therefore, in the case of an uncompressible fluid which is the assumption for the $\rho=\rho_{o}$, simulations and a hydrostatic pressure condition may be established: Pressure Outlet: $P^{\prime}=0$.

\section{Results of the simulation}

Figs. 6 and 7 show examples of the results obtained after simulating the bollard pull test in the selected tugboat. As shown, the pressure as well as the viscous stress that cause water movement around the propellers and the duct can be reproduced.

\section{Result validation}

Fig. 8 (see page 18) shows a comparison between the torque obtained using simulation and that obtained using theoretical analysis for the different propeller duct combinations. As shown in the figures, the difference between the numerical and theoretical results is small, and it can therefore it can be ensured that the model developed is appropriate for simulation of bollard pull tests for tugboats.

\section{Conclusions}

This article has successfully proven an analysis 
Fig. 6. Pressure outlet: Suction side (left), Pressure side (right).

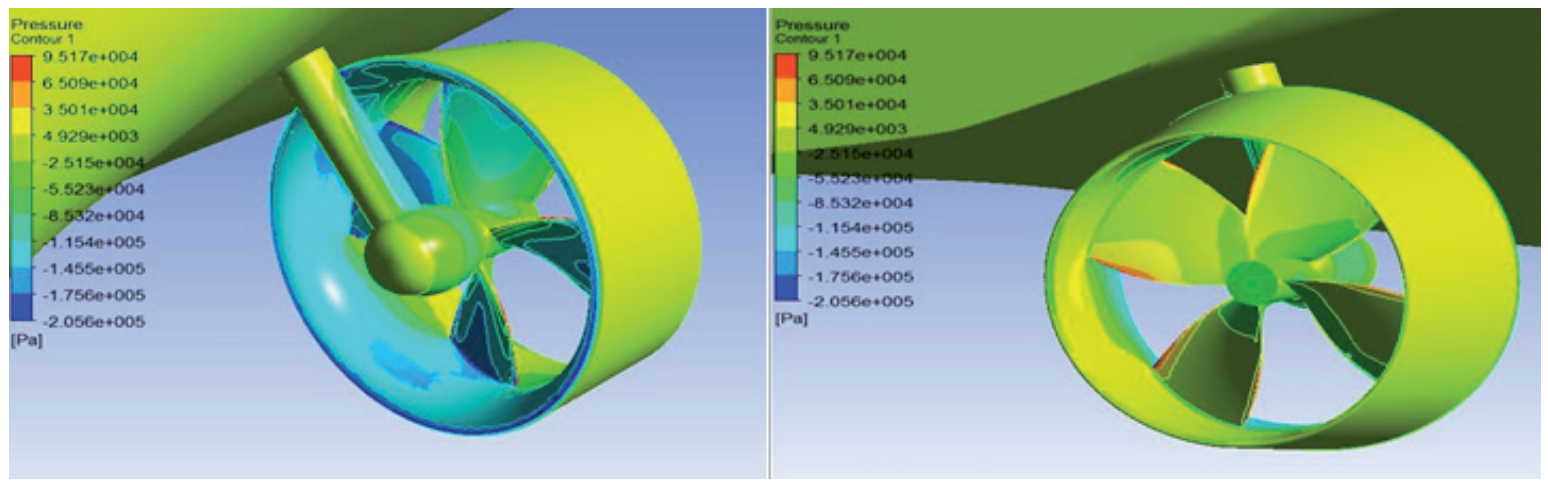

Fig. 7. Viscous pressure outlet: Suction side (left), Pressure side (right).

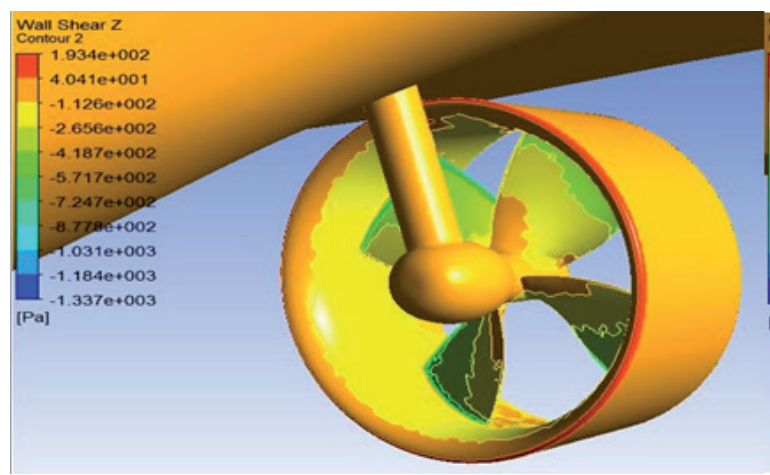

methodology to simulate bollard pull tests for vessels, taking into account the propellerduct set and its interaction with the hull. The methodology's efficacy was proven through validation of the simulation results to the expected theoretical response. The code was developed using the results of the finite volumes of Ansys Fluent, which achieved replication of bollard pull tests that are similar to the real ones. We may conclude that using this mathematical model the bollard pull test may be reproduced successfully during the design process, thus saving time and money and preventing future complications once the vessel is built.

\section{Acknowledgements}

The authors wish to thank the National Science and Technology Secretariat (SENACYT) and CLASS IBS for their support during this investigation.

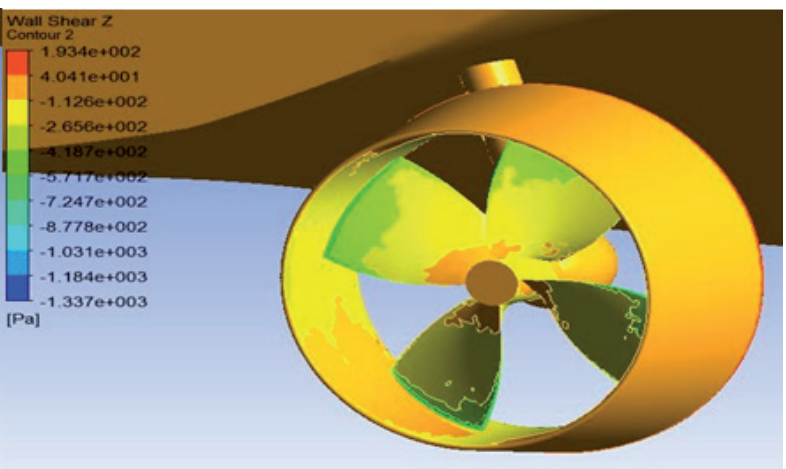

\section{References}

[1]. I. TREJO, M. TERCEÑO, J. VALLE, A. IRANZO, J. Domingo, Analysis of a ship propeller using cfd codes. Calculation of the resistance and the wave profile of a $3600 \mathrm{TEU}$ container ship. 2007.

[2]. F. PACURARU, A. LUNGU, C. UNGUREANU and O. MARCU, Numerical simulation of the flow around a steerable propulsion unit. 25th IAHR Symposium on Hydraulic Machinery and Systems. 2010.

[3]. ING. LEONEL GALEANO VASCONCELOS, DR. C. ING. ALEJANDRO P. PRIETO FERNÁNDEZ, DR. C. ING. CARLOS ALEXANDER RECAREY MORFA. Experimentos Numéricos CFD en Propulsión Naval. VII Symmtechnaval 2012. IPIN Cuba. 
[4]. J. MARTÍNEZ DE LA CALLE, J. GONZÁLEZ PÉREZ, L. BALBONA CALVO, E. BLANCO MARIGORTA, Análisis del flujo en una hélice marina. Comparación de los resultados numéricos con las medidas experimentales. 2002.

[5]. ISAO FUNENO, Hydrodynamic Optimal Design of Ducted Azimuth Thrusters. First International Symposium on Marine Propulsors smp'09, Trondheim, Norway, June 2009.

[6]. DR PAUL MERTES, HANS-JÜRGEN HEINKE, Aspects of the Design Procedure for Propellers Providing Maximum Bollard Pull. Suntec Convention Centre, Singapore Organised by the ABR Company Ltd. 2008.
[7]. W.H.LAM,D.J.ROBINSON, G.A.HAMILL, Y H.T.JOHNSTON, An effective method for comparing the turbulence intensity from LDA measurements and CFD predictions within a ship propeller jet. 2012.

[8]. ABDEL-MAKSOUD, M., HEINKE, H.-J. (2002). Scale Effects on Ducted Propellers. 24th Symposium on Naval Hydrodynamics. Fukuoka, Japan.

[9]. HUANG SHENG, ZHU XIANG-YUAN, GUO CHUN-YU, and CHANG XIN. CFD simulation of propeller and rudder performance when using additional thrust fins. Journal of Marine Science and Application, Vol.6, No.4, December 2007.

Fig. 8. Torque for propeller-duct configuration of a) 1 meter, b) 1.5 meters, c) 2 meters, d) 2.5 meters
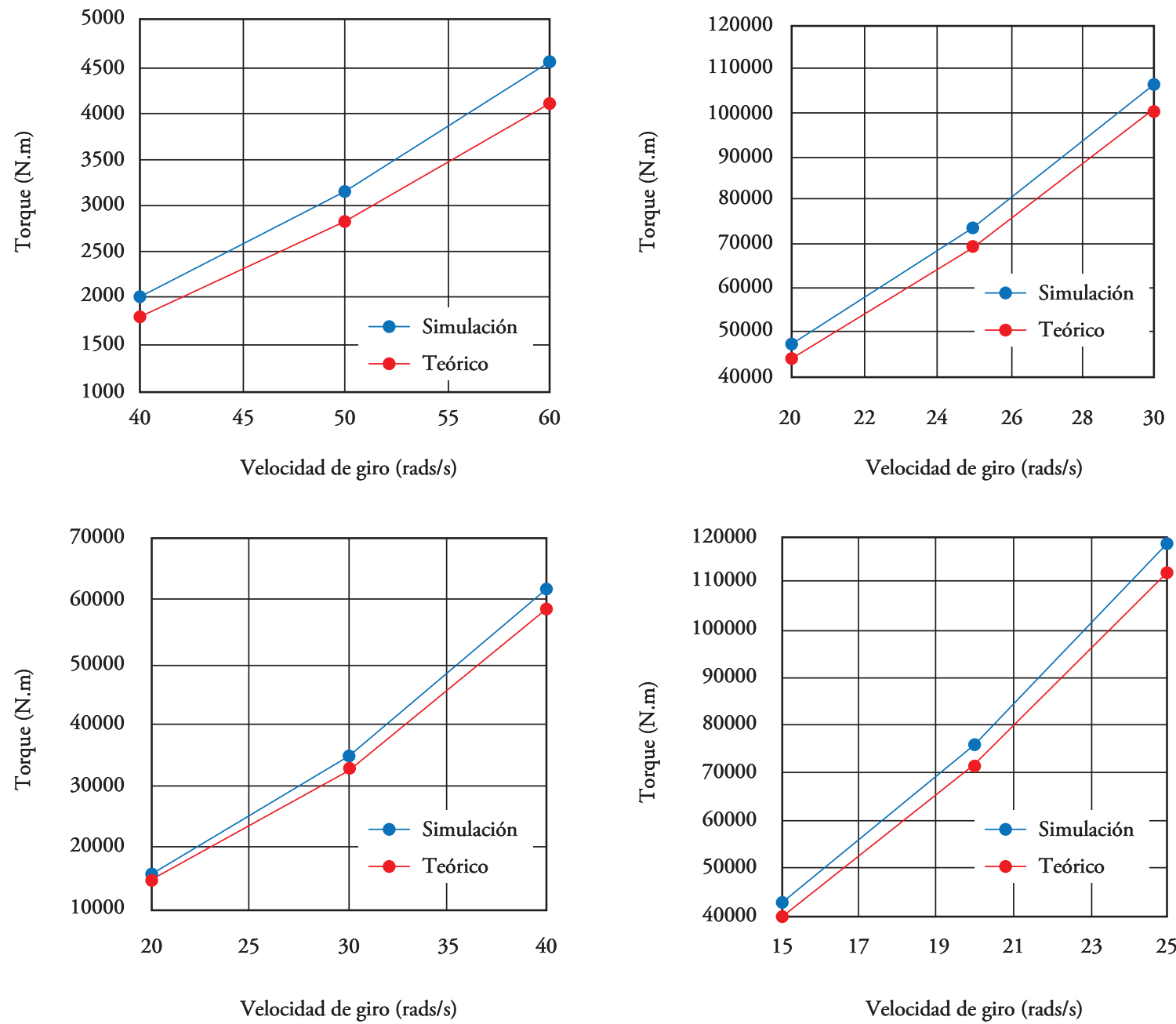